POLLACK PERIODICA

An International Journal for Engineering and Information Sciences

DOI: $10.1556 / 606.2019 .14 .3 .1$

Vol. 14, No. 3, pp. 3-10 (2019)

www.akademiai.com

\title{
FROM TRADITIONAL SYMBOL TO NEW CONTEMPORARY FORM
}

\author{
${ }^{1}$ Qian ZHANG, ${ }^{2}$ Akos HUTTER* \\ ${ }^{1}$ Marcel Breuer Doctoral School, Faculty of Engineering and Information Technology \\ University of Pécs, Boszorkány u. 2, H-7624, Pecs, Hungary \\ and Department of Environment Art Design, School of Art and Design \\ Hubei University of Technology, Wuhan, China, e-mail: 918880856@qq.com \\ ${ }^{2}$ Department of Architecture and Urban Planning, Institute of Architecture \\ Solidarity in Architecture Research Group, Faculty of Engineering and Information \\ Technology, University of Pécs, Boszorkány u. 2, H-7624 Pécs, Hungary \\ e-mail: huttera@mik.pte.hu
}

Received 11 December 2018; accepted 31 March 2019

\begin{abstract}
The main design strategies of this Chinese project are connection and aesthetic. The new annex building conference and meeting center - presents the new contemporary form and sets up a new relationship with the original stadium surrounding and local traditional culture. The traditional symbol - 'Lotus Flower' is used as an effective design imagines, and it was transferred into contemporary form to create the new functional space and attractive volume. This project is a great possibility to explore the methods how traditional and cultural elements can show up in up-to-date way in contemporary architecture.
\end{abstract}

Keywords: Connection, Symbol, Contemporary form, Function, Humanization

\section{Introduction}

\subsection{General introduction}

Last spring School of Arts and Design of Hubei University of Technology was asked to develop a conception of extension of Wuhan Stadium by Wuhan Sport Center. The purpose of client is to establish a new Conference and Meeting Center (CMC) for the $7^{\text {th }}$ Military World Games, which will be held in 2019. The new development was inspired to accommodate the main meeting, conference hall, smaller meeting rooms, restaurant, cafeteria and additional functions.

${ }^{*}$ Corresponding Author 
Since 1995 , the $1^{\text {st }}$ Military World Games was held in Rome. This world games International Military Sports Council (Conseil International du Sport Militaire) (CISM) has become, with its 133 member nations, its annual world, continental and regional sports calendar and the high level of its competitors, one of the biggest sports institution in the world [1].

For the $7^{\text {th }}$ Military World Games, Wuhan city - the largest city in the middle of China - will develop several stadium projects basically completed to the satisfaction of the games in 2019.

This project is a multifunctional annex building of the existing main stadium, which can serve efficiently for the stadium during the CISM, and also can be taken full advantage after the Military World Games.

The existing stadium - Wuhan Sport Center Stadium was constructed with 52,672 people capacities between 1999 - 2002, announced initially to hold 60,000 people, it proved to be significantly smaller, but still sufficient for domestic football needs. This ground hosted games of the 2007 Women's World Cup. The roof is its most distinctive part, supported by four concrete pillars; its curved steel frames support a light membrane cover. The structure was co-created by Birdair, a global leader in tensile covers. Apart from the main stadium the complex comprises two large indoor arenas, secondary athletic stadium and two football fields. This building is a good example of high quality contemporary stadium architecture with elegant, modern appearance and high-tech structural solutions, as it is shown in Fig. 1.

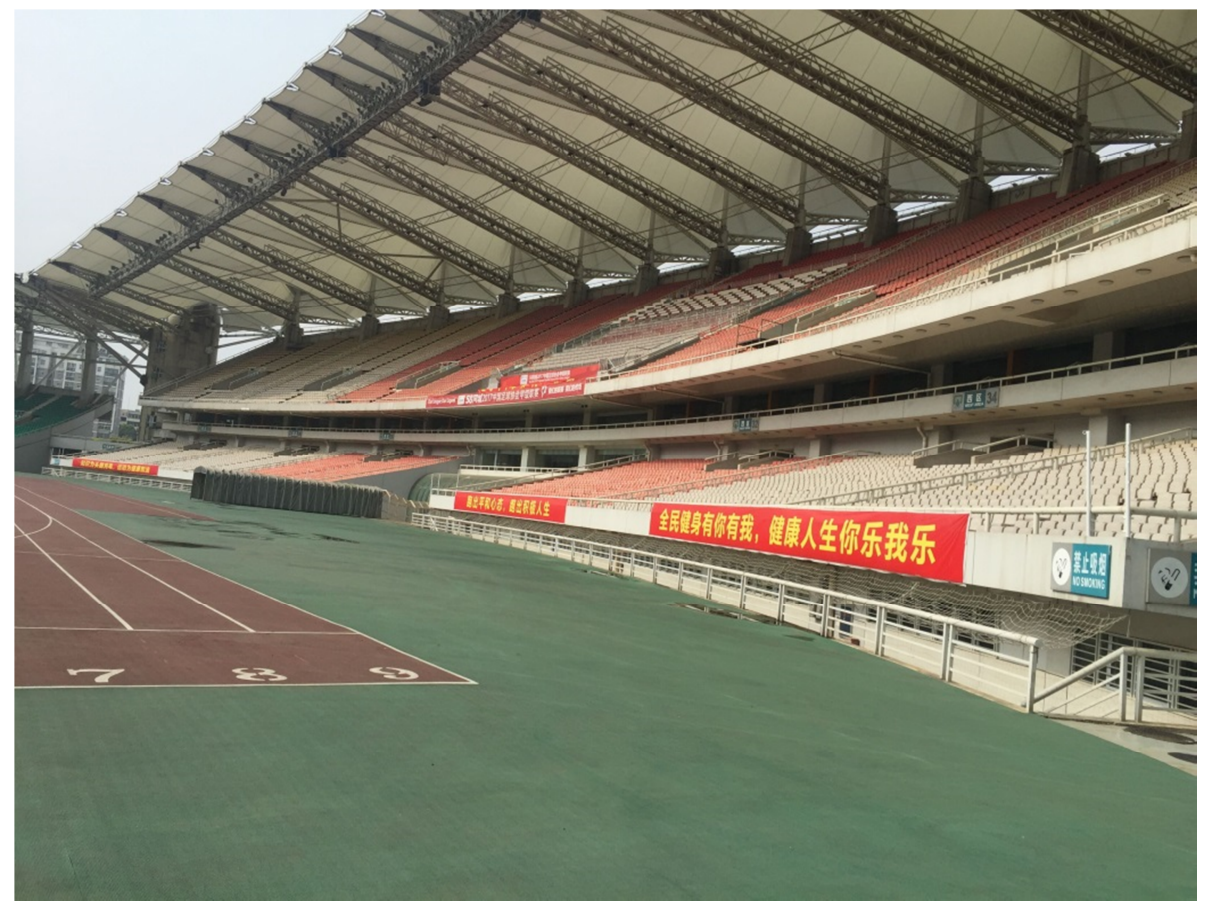

Fig. 1. Wuhan Sport Center Stadium (Photo: Author)

Pollack Periodica 14, 2019, 3 


\subsection{Requirements of the project}

One of the main challenges of this project is to come up with right connection between the existing main stadium building and new extension. The client claimed the new building has to present a beautiful form and integration with its environment, and it should have official appearance and strong functional connection with the existing stadium. The new member of sport center is also expected to fit the contemporary surrounding.

The other main challenge in this project is that the new architectural conception must comprise traditional Chinese elements as well. The intent of client for the proposed building is that it should refer to the characteristic of Wuhan city and also the spirit of CISM game.

\section{Design conception}

\subsection{Symbols in China}

As it is well known, symbolic culture is an outstanding characteristic in Chinese culture, aesthetics and traditional architecture [2]. CISM game is significant for Wuhan city, so the project is supposed to present the symbolic culture to some extent, to manifest unique spirit of the city, and to bring luck for the city as well.

Being a city of river and a city of lakes, Wuhan is naturally connected with the impression of water, and it is also famous for the sights of a mass of lotus flower in the summer. Lotus is a sort of popular flower and an important symbol in China. It has rich meaning and metaphors, and symbolizes divinity, peace, fertility, wealth, knowledge and being enlightenment.

Considering the theme of CISM at the same time, the design conception was inspired by the spirit of city and classic Chinese cultural motifs such as lotus flower and its branch, and natural rural landscape's feature of this province as well.

\subsection{Transformation of symbols}

For the initial idea of designer team, the proposed building together with the stadium are appeared in an organic system for which was created by a new landscape, a garden between them. The integral link between the main elements of composition is conceived as several branches of lotus flowers in traditional Chinese ink paintings. And the proposed new conference building is figured as bloom of the flower, as it is shown in Fig. 2. The symbolic meaning of lotus flower is essential in Chinese culture and it has especial importance in the city of Wuhan's cultural background as mentioned above. Another inspiration of the landscape conception was the formation of Chinese stepped farmland, the beautiful, picturesque terraces on slopes of mountains.

The sunken garden between stadium and proposed conference building is conceived like a terraced farmland with intensive vegetation and water surfaces. The green fields are located in different levels. The bridges and pathways serve as observation points and they provide different perspectives to the building and its surrounding. A roofed 
corridor at the sunken garden level between the stadium and conference building materializes the required functional connection.

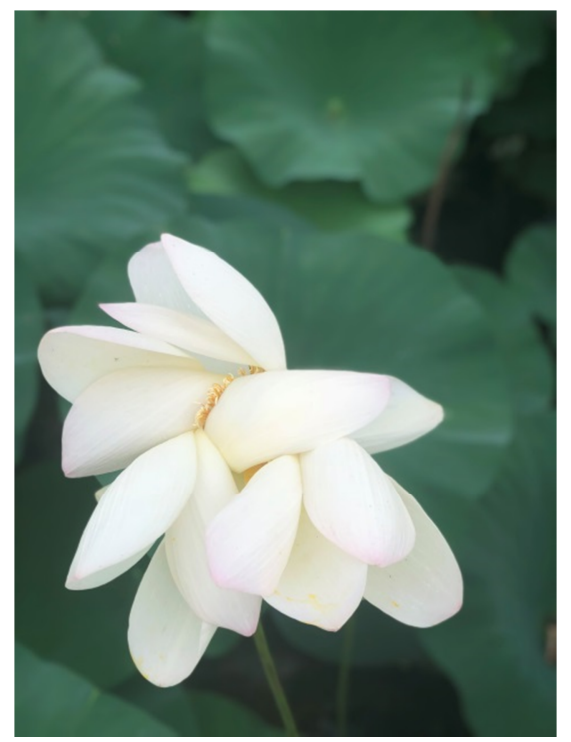

Fig. 2. Lotus flower in Wuhan (Photo: Author)

\section{A new architectural form}

\subsection{Contemporary form of symbols}

The essential point of conception was to utilize transparent and translucent building materials and surfaces with different lighting conditions in interior and outdoor places. The illuminated appearance is also a significance due to usual nighttime of events likewise the existing stadium building. The applied translucent glazed facades guarantee unified lighting conditions in the interior spaces; furthermore this surface is able to visualize traditional Chinese ink paintings in a contemporary understanding, as it is shown in Fig. 3.

The effect of Chinese brush painting was applied to emphasize the main entrance of the building. The gently smooth shape of different roof partitions forms the petals of lotus flower and the white surfaces, and both parts can get different tones by illuminating colors, as it is shown in Fig. 4.

\subsection{New sustainable energy conception}

Sustainability and green-energy technical solutions are a pivotal in this conception. Beyond the well-organized functional system and effective building structure, the conception was focused on natural ventilation and economical cooling and heating system of interior spaces. 


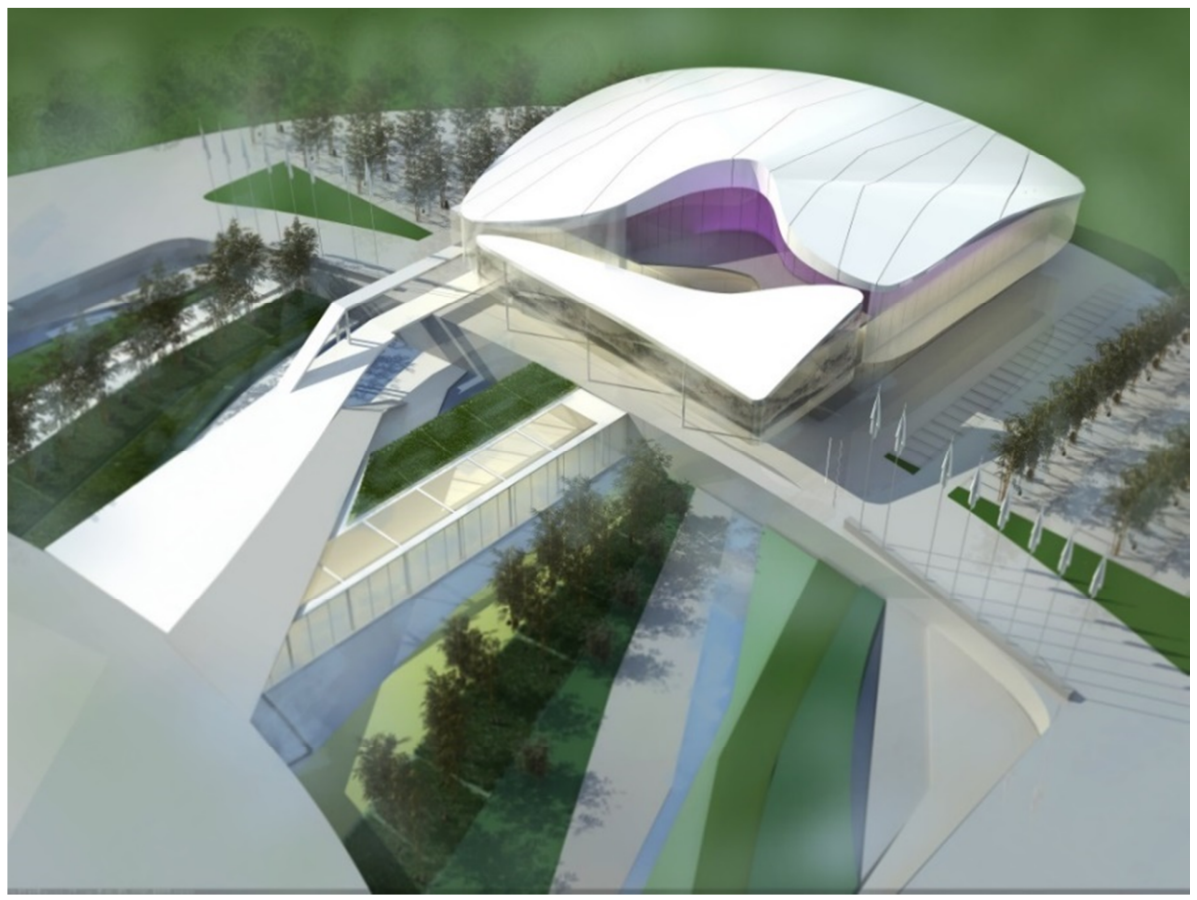

Fig. 3. Conference building and garden (Source: designed by Author)

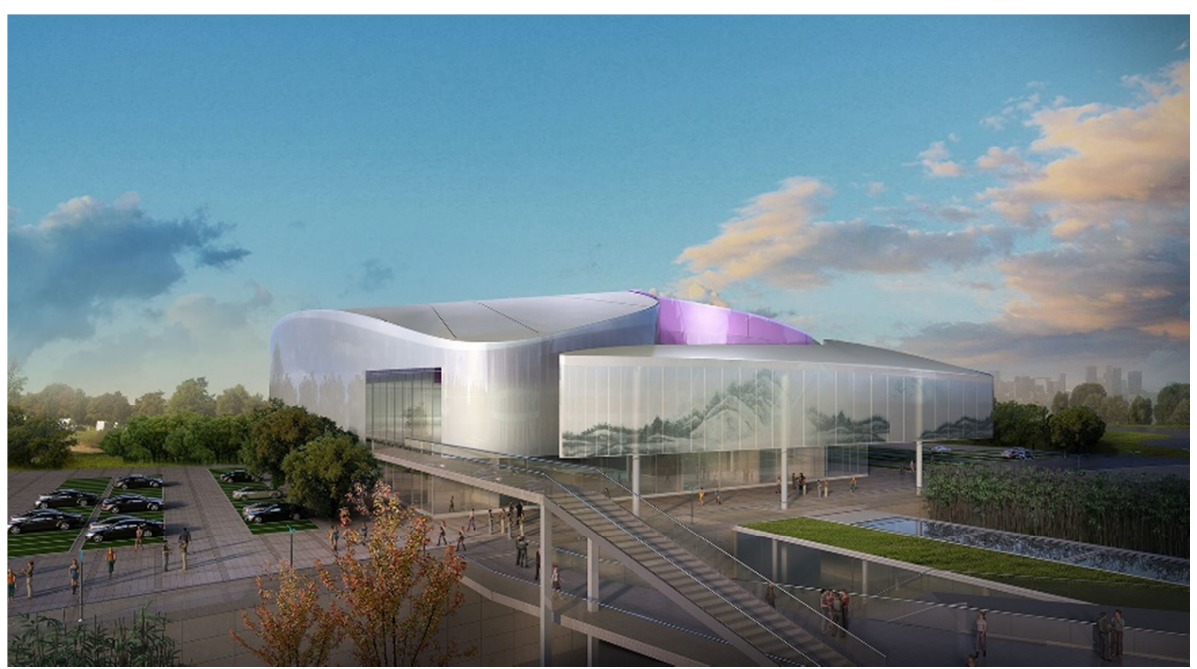

Fig. 4. Main entrance of conference center (Source: designed by Author)

Basically, a well-known technical solution was applied to exploit passive solar energy during wintertime and increase the cooling effect of ventilation in summer. The 
double glazed façade system - with buffer zone between them - is able to enhance the comfort level of interior spaces by natural resources. In addition, geothermal energy system was also suggested to the building. More efficient cooling and heating system can be developed by the opening and closing of buffer-air layer, and by application of shading structure between the façade surfaces, as it is shown in Fig. 5. Besides the construction budget, usually the cost of building maintenance is also a serious expense item, which also can be decreased by the proposed energy conception [3].

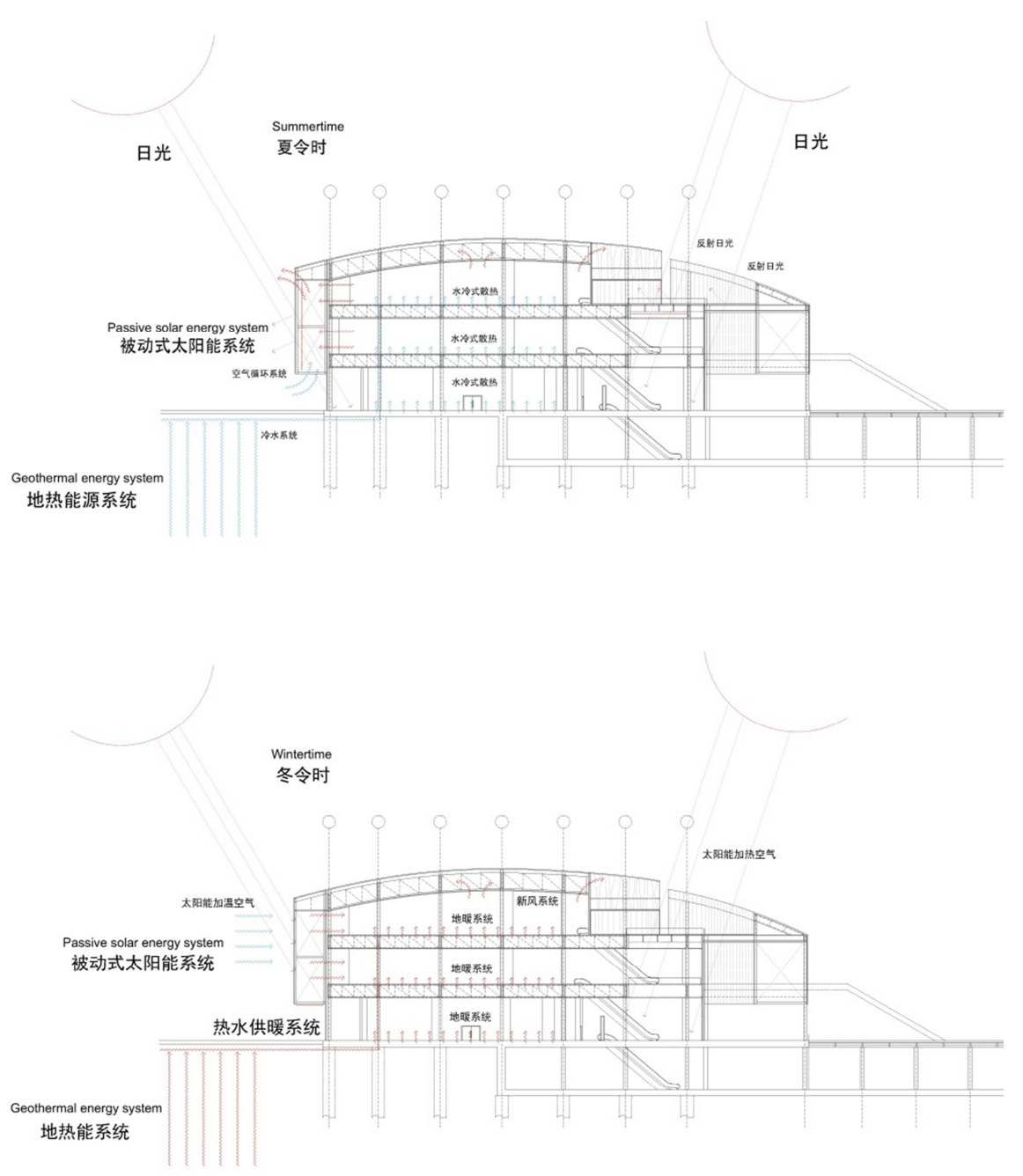

Fig. 5. Cross section, building energy conception diagram (Source: designed by Author) 


\section{Contemporary symbolism}

Different cultural background and traditional elements have to be considered even in contemporary architectural and urban development projects nowadays [4]. In this project, the conception was inspired by the local traditional symbolic culture instead of ignoring it. During the design process, the proposal was influenced by the meaningful traditional symbols increasingly. Due to the rich content of symbols, extraordinary contemporary architectural form was resulted, which was more complex, it had close formal and contextual connection with the high quality existing stadium, and also it was accepted by the client.

On one hand, traditional symbol could inspire the conception of the proposal, and it also could motivate the new contemporary form of the space. This inspiring design method was applied during the whole architectural planning process in this project. It was a great possibility to explore the methods of how traditional, cultural elements can show up in an up-to-date way in contemporary architecture.

On the other hand, it is very frequent case when the architectural form is overemphasized or even the function of building is sacrificed due to complex formal solution in Chinese contemporary architecture. The appearance of the ubiquitous 'iconic buildings' mainly visual landmarks follow the will of decision-makers blindly often in China [5]. The 'aesthetic determinism' leads architecture to pursue appearance puerilely, while the internal quality - the proportion, scale, sound, light and atmosphere of space - have become a secondary problem. In China, architectural design gives the impression of low level of creativity and imperfect design results to clients, unless the design conception derives from cultural symbols or traditional images.

Generally, the superficial visual symbols and irrelevant moral contents are highlighted in modern landmark architectural developments instead of the sense of space from the aspects of citizens.

'Form and function' is an eternal topic in architectural design. In any cases, it is very important to get the true equilibrium between form and function. Architecture means constantly connecting with the real world at the moment, carrying aesthetic forms in the functions of architecture. Then architecture could go back to eternity, bring new insights to the reality, and enrich the whole world [6].

The interweaving of function, aesthetics and humanization of modern city space were processed according to the intention of design team in this architectural project. Those technical answers like application of renewal energy resources in building energy system also contribute to make a possible humanized and eternal architectural space.

\section{Conclusion}

Architecture has its responsibility of reveal the truth of its surroundings and the times meanwhile it has to be powerful magnets with distinctive appeal. Traditional symbol is an effective and no negligible material of creating attractive form.

Going back to the function and the essence is the key of how architecture could transform traditional symbol into the contemporary form. It is important to find the right balance between appearance of symbolic images in architecture and rational and 
reasonable solution in the buildings. The physical and metaphysical quality of space can be emphasized in the same time by serving equilibrium of technical and cultural aspects of architecture otherwise human being will always feel lack of comfort in built spaces.

\section{Acknowledgements}

This paper was built on the project design of Conference Center of Wuhan Sport Center, the whole design process was supported by Marcel Breuer Doctoral School University of Pécs, Hungary and Department of Environment Art Design, School of Art and Design, Hubei University of Technology, China.

\section{Open Access statement}

This is an open-access article distributed under the terms of the Creative Commons Attribution 4.0 International License (https://creativecommons.org/licenses/by/4.0/), which permits unrestricted use, distribution, and reproduction in any medium, provided the original author and source are credited, a link to the CC License is provided, and changes - if any - are indicated. (SID_1)

\section{References}

[1] 7th Military World Games (MWG), http://www.wuhan2019mwg.cn/, (last visited 5 December 2018).

[2] Wang H. The significance of phenomena - phenomenology and contemporary architectural design thinking, Architectural Journal, Vol. 592, No. 1, 2018, pp. 74-79, www.aj.org.cn, (last visited 5 December 2018).

[3] Mozsonics E., Kistelegdi I. Typological investigation of climate systems and design of multifunctional shading structures for the facade of the Szentágothai Research Center, Pollack Periodica, Vol. 10, No. 1, 2015, pp. 61-70

[4] Zhao D., Bachmann B., Wang T. Architecture and landscape design for Beikanzi village in China: an investigation of human settlement and environment, Pollack Periodica, Vol. 13, No. 2, 2018, pp. 231-236.

[5] Meng J. A humanistic design philosophy, World Architecture, Tsinghua University Press, ISSN 1002-4832, Vol. 316, No. 10, 2016, pp. 22-25.

[6] Kahn L. I., Lobell J. Between silence and light: Spirit in the architecture of Louis I. Kahn, Shambhala Publications Inc, $2^{\text {nd }}$ ed, 2008. 